\title{
Reducing the Disconnect: Medical Students' Role in Aligning Health Care with 21st Century Values
}

TARA SURESH (1)

*Author affiliations can be found in the back matter of this article

\section{ABSTRACT}

Patient-centered care has been a focus of health care for decades but physicians' consideration of patient perspective through trauma informed care started recently. Trauma is not just limited to physical and mental spheres but also social, cultural, racial, and economic realms of a patient's life. Despite understanding the multifaceted aspect of trauma, physicians, when stressed, continue to prioritize their expertise and patient compliance over understanding the individual circumstance that led to a difference in patient values and priorities, focusing on the science over the art of medicine. This model leads to a lack of trust between the physician and patients and worse outcomes due to an incomplete understanding of the patients' prior experiences. Medical students are now trained in their consideration of community and social and structural determinants of health, educated to recognize that the hospital care is only a small factor in a patient's overall health. Medicine is on the brink of change, attempting to use feminist and narrative ethics rather than principlism to justify deviance from precedence. However, the speed of this transition depends on a conservative field's ability to adjust, a somewhat paradoxical predicament. Medical students can play a major part in this transition, utilizing their novelty to the field to prevent experience's penchant for uninhibited traditionalism. Promoting medical students to lead the charge in this transition upends the hierarchy of education, which may bruise egos of Attending Physicians who view their methods as the only way to achieve the best results given the reality of limited time for individual patient interactions. While daunting due to existing medical hierarchy, medical students need to push the profession to a new modus operandi, founded on the significant contribution of the entire patient's experience to the issues at hand and the understanding of the patient's journey within the health care system.

CORRESPONDING AUTHOR:

\section{Tara Suresh}

Washington University School of Medicine in St. Louis, US

tsuresh@wustl.edu

\section{KEYWORDS:}

Medical Hierarchy; Medical Education; Trauma Informed Care; Clinical Ethics;

Accountability

\section{TO CITE THIS ARTICLE:} Suresh T. Reducing the Disconnect: Medical Students' Role in Aligning Health Care with 21st Century Values. ISMMS Journal of Science and Medicine. 2021; 1(1): 12, pp. 1-2. DOI: https://doi. org/10.29024/ijsm.42 
The author has no competing interests to declare.



and Medicine

DOI: $10.29024 /$ ijsm. 42

\section{AUTHOR AFFILIATION}

Tara Suresh (iD) orcid.org/0000-0003-0226-7182

Washington University School of Medicine in St. Louis, US

TO CITE THIS ARTICLE

Suresh T. Reducing the Disconnect: Medical Students' Role in Aligning Health Care with 21st Century Values. ISMMS Journal of Science and Medicine. 2021; 1(1): 12, pp. 1-2. DOI: https://doi. org/10.29024/ijsm.42

Submitted: 29 December 2020 Accepted: 29 December 2020 Published: 25 January 2021

COPYRIGHT:

(C) 2021 The Author(s). This is an open-access article distributed under the terms of the Creative Commons Attribution 4.0 International License (CC-BY 4.0), which permits unrestricted use, distribution, and reproduction in any medium, provided the original author and source are credited. See http://creativecommons.org/ licenses/by/4.0/.

ISMMS Journal of Science and 